\title{
Physicians and euthanasia: a Canadian print-media discourse analysis of physician perspectives
}

\author{
David Kenneth Wright PhD, Jennifer R. Fishman PhD, Hadi Karsoho BA, Sarah Sandham MA, \\ Mary Ellen Macdonald $\mathrm{PhD}$
}

\section{Abstract}

Background: Recent events in Canada have mobilized public debate concerning the controversial issue of euthanasia. Physicians represent an essential stakeholder group with respect to the ethics and practice of euthanasia. Further, their opinions can hold sway with the public, and their public views about this issue may further reflect back upon the medical profession itself.

Methods: We conducted a discourse analysis of print media on physicians' perspectives about end-of-life care. Print media, in English and French, that appeared in Canadian newspapers from 2008 to 2012 were retrieved through a systematic database search. We analyzed the content of 285 articles either authored by a physician or directly referencing a physician's perspective.

Results: We identified 3 predominant discourses about physicians' public views toward euthanasia: 1) contentions about integrating euthanasia within the basic mission of medicine, 2) assertions about whether euthanasia can be distinguished from other end-of-life medical practices and 3) palliative care advocacy.

Interpretation: Our data showed that although some medical professional bodies appear to be supportive in the media of a movement toward the legalization of euthanasia, individual physicians are represented as mostly opposed. Professional physician organizations and the few physicians who have engaged with the media are de facto representing physicians in public contemporary debates on medical aid in dying, in general, and euthanasia, in particular. It is vital for physicians to be aware of this public debate, how they are being portrayed within it and its potential effects on impending changes to provincial and national policies.

anadian society is on the verge of enacting change to the spectrum of medical practices legally provided at the end of life. ${ }^{1,2}$ Physicians, deeply implicated in and by these changes, are an authoritative stakeholder group whose opinions can hold sway with the public. Outside of Canada, there has been some scholarly attention paid to physicians' experiences of and attitudes toward euthanasia as a medical practice. ${ }^{3,4}$ Our goal was to systematically examine the portrayal of physicians' attitudes about euthanasia in Canadian print media.

Our use of the term euthanasia mirrors that of Rietjens and colleagues, ${ }^{5}$ who provide the following terminological clarifications based on Dutch law:

In the Netherlands, euthanasia has been defined since 1985 as the administration of drugs with the explicit intention to end life at the explicit request of a patient. Physician-assisted suicide is defined as the administration, supply or prescription of drugs with the explicit intention to enable the patient to end his or her life. Euthanasia and physician-assisted suicide are therefore to be distinguished from other medical decisions concerning the endof-life; such as withdrawing or withholding potentially lifeprolonging treatments; intensified measures to alleviate pain or other symptoms while taking into account the possible hastening of death or appreciating that possibility; or actively ending the patient's life without an explicit request. (p. 272)
Although euthanasia and physician-assisted suicide are different practices, they are both distinguished by the deliberate participation of a physician in acquiescing to patients' requests to actively end their lives. ${ }^{6}$ Therefore, when we use the term euthanasia, we are also referring to physician-assisted suicide.

The objective of this study was to synthesize and analyze how physicians' perspectives appear in articles about euthanasia within Canadian print media. This analysis showed how physicians are represented and, therefore, what the public gleans about how physicians feel about euthanasia in Canada. Although the perspectives of those physicians who engage with the print media are unlikely to accurately or comprehensively represent how physicians, individually or collectively, feel about euthanasia, ${ }^{7}$ the overall picture presented to the public reflects back onto attitudes about physicians as a whole - influencing public perceptions of and trust in medical professionals during these changing times.

\section{Competing interests: None declared.}

This article has been peer reviewed.

Correspondence to: Jennifer Fishman, jennifer.fishman@mcgill.ca CMAJ Open 2015. DOI:10.9778/cmajo.20140071 


\section{Methods}

\section{Design}

This paper presents a discourse analysis of print media reporting on end-of-life care. Discourse analysis is premised on the assumption that language (i.e., words, their meanings and implied values) both reflects and shapes our reality. ${ }^{8}$ It is a qualitative research methodology that has been proven useful for understanding ideologies of health and illness through analysis of the uses of language. ${ }^{9,10}$ First, it is necessary to look for thematic patterns in the textual dataset. These themes are then analyzed by paying attention to their meaning, how they are constructed or framed and their variability across the dataset.

\section{Data sources}

We performed a systematic search of 2 large databases, Canadian Newsstand and Newscan.com. Canadian Newsstand includes nearly 300 Canadian newspapers - national, provincial and local. We augmented this search with Newscan.com to capture French-language newspapers, which are underrepresented in Canadian Newsstand. Search terms included "euthanasia," "physician-assisted suicide," "withholding and withdrawal of treatment," "palliative sedation," as well as related terms (e.g., "mercy killing," "right to die," "withdrawal of care"). For the analysis detailed here, we present a subset of our data focusing on representations of physician perspectives. To do so, we only included articles from the database that were either 1) authored by a physician or 2) referenced a physician's perspective (i.e., an individual physician or professional medical association) within the article.

\section{Analysis}

Each of the articles was coded by members of the research team using ATLAS.ti, a software program designed to sort and manage qualitative data. Coding at this initial stage was inductive and descriptive; each article was read line by line, and initial codes were applied to facilitate the identification and categorization of topics portrayed in the media. A codebook was generated in which each code was defined and then refined by team members during coding meetings to ensure team consensus.

These articles were read again by one team member (D.K.W.) alongside the initial coding schema. Coding at this stage was analytic; new codes were applied to identify patterns and themes with respect to how Canadian physicians are represented within media coverage about euthanasia. All of the authors participated in regular coding meetings about emerging themes and developed a categorization scheme of the results. No major substantive differences were observed between the sets of English and French articles. Finally, all of the English articles were reread by 2 authors (D.K.W. and H.K.) to verify the identified themes and to ensure that nothing substantial was omitted from the analysis.

Ethics approval for this study was obtained from the McGill Institutional Review Board of the Faculty of Medicine.

\section{Results}

Our database search yielded a dataset of 1913 print-media articles, published between 2008 and 2012. For this analysis, 285 articles that reported a physician's perspective were included. Most of these articles were news articles $(n=153)$, letters to the editor $(n=61)$ and opinion pieces $(n=63)$. There were also a small number of editorials $(n=8)$. There were 98 unique physician voices represented across our data; many of the voices were not identified with any particular specialty $(n=41)$ in the media. Of the specialties identified, the most common was palliative care $(n=33)$, followed by family medicine $(n=11)$ and oncology $(n=7)$. Specialty categories were not mutually exclusive; for example, a physician may have been identified both as representing palliative care and oncology in a media article. Surgery, internal medicine, geriatrics, neurology and psychiatry were all represented 3 or fewer times in our data. Additionally, some of the physicians in our data were referred to as representing advocacy and professional bodies, and some of the articles quoted such bodies without naming an individual physician. No independent verification of a physician's specialty or affiliation was conducted; our focus was on the media's portrayal of these physician voices.

Our analysis identified 3 predominant discourses concerning physician perspectives on euthanasia: 1) contentions about integrating euthanasia within the basic mission of medicine, 2) distinguishing euthanasia from other end-of-life medical practices and 3) palliative care advocacy. Physicians were represented in our media data as equivocal about the ethics of euthanasia, yet were more likely to speak out against its legalization through one of these discourses.

\section{Contentions about integrating euthanasia within the basic mission of medicine}

Local, provincial and national articles were frequently devoted to coverage of the Quebec context: in 2009, the Collège des médecins du Québec adopted a position in favour of opening up a social discussion about euthanasia as a legitimate end-oflife care option. ${ }^{11}$ Also in that year, media coverage had begun about membership surveys that were conducted among the Fédération des médecins spécialistes du Québec and the Fédération des médecins omnipraticiens du Québec, both of which purportedly established that the majority of physicians within these groups endorsed euthanasia as a potentially legitimate medical practice. Within this discourse of "physicians in favour" was the message that euthanasia is a legitimate care practice (Box 1) and that policy reform would align medical ethics with the will of the public, given repeated public opinion polls in Quebec and Canada that show high support for the legalization of euthanasia.

Although the coverage of the Quebec medical associations gave rise to an overall discourse of physicians in favour, a reading of individual perspectives challenged the interpretation of unified physician support. Indeed, in our analysis of letters to the editor and quotations in news articles, some_individual physicians in the media were positioned against the view that euthanasia could ever constitute ethical care. References were 
made to medicine's basic mission as healing and protecting life and to euthanasia as fundamentally conflicting with this mission (Box 1). Furthermore, individual physicians engaged the media to challenge the validity of the surveys conducted by the Fédération des médecins spécialistes du Québec and the Fédération des médecins omnipraticiens du Québec, citing low response rates and biased questions, thereby questioning the conclusion that physicians in Quebec support euthanasia. These physicians cautioned the public that the Quebec medical associations may not faithfully portray the perspectives of Canadian physicians as a whole because they thought that they had been falsely represented in the publicity generated by publication of the results of these surveys.

Physicians' arguments against legalizing euthanasia, as presented in the media, explicitly sought to undermine the very logic of euthanasia as care. First, physicians expressed a concern that euthanasia as medical therapy would irrevocably destabilize the trust that society confers upon them as healers (Box 1). Another argument was that the notion of desire for death is too complex to be understood simply from a perspective of individual choice or freedom. Physicians making this argument suggested that their role compels them to never accept at face value a patient's wish for a hastened death. Rather, their role as healer is to understand and to respond to the motivations that underlie such a wish (Box 1).

Another common argument made against euthanasia was based in consequentialist reasoning that the potential harms to society that may arise necessarily outweigh any potential benefit to individual patients. Although the Quebec medical associations were represented as advocating euthanasia as a stringently safeguarded practice, individual physicians argued that evidence from other jurisdictions that have legalized euthanasia proved that the safeguards were not working. Furthermore, these physicians predicted that the most vulnerable within our society (e.g., older patients, patients with disabilities) would submit to covert social pressures to request euthanasia.

Some physicians were represented in the media as supportive of euthanasia. For example, within the discourse on the ethics of care was the concern that the illegality of euthanasia constrains the horizon of therapeutic possibilities at the end of life. This constraint was portrayed as a limit to a physician's ability to ethically attend to suffering (Box 1).

\section{Distinguishing euthanasia from other end-of-life medical practices}

In media representations about end-of-life care, specific medical practices (i.e., euthanasia, the withholding or withdrawal of life-prolonging treatment, pain relief and palliative sedation) were regularly equated as one phenomenon. In one example (Box 2), the journalist reported that the use of opioids and withholding life-prolonging treatment were conceptually equivalent to euthanasia. For individual physicians in our analysis, depictions such as these were a source of frustration because they are conceptual conflations. These physicians contended that euthanasia is a distinct practice that must be ethically distinguished from practices of withholding and withdrawing life-sustaining treatment, administering opioids in proportion to patient suffering, and palliative sedation. They suggested that the crux of the ethical difference is that only with euthanasia is the patient's death deliberately intended. Importantly, it is not only the lay public whom they accused of committing such conflations, but also other physicians.

We saw examples of this conflation in the media's coverage of the physicians-in-favour discourse. The Quebec medical associations promoted the idea that physicians were vulnerable to criminal prosecution in their attempts to deliver appropriate end-of-life care (Box 2). However, delineating the practices discussed here from conventional definitions of euthanasia is an important educational activity for other physicians engaging with media (Box 2). This point of contention among physicians served to contextualize this discourse and suggested a rationale for why physicians may feel compelled to engage the media to clarify such conceptual understandings.

\section{Palliative care advocacy}

The representations of physicians identified as palliative care specialists within the media collectively created a unified discourse. In this discourse, euthanasia was opposed on the grounds that optimal end-of-life care obviates the need for

Box 1: Contentions about integrating euthanasia within the basic mission of medicine

According to Dr. Yves Robert, secretary of Collège des médicins du Québec, "death can be an appropriate type of care in certain circumstances." 12

"Dr. Bolduc [then health minister of Quebec] is familiar with the issue. Just before entering politics last June, Dr. Bolduc, who had practised medicine for 25 years, co-wrote a book entitled Mourir dans la dignité (Dying With Dignity), in which he argued the 'door should be left open in some particular cases which could justify a positive response' for assisted suicide."13

"We did not enter the field of medicine and nursing to learn when to dispatch our patients when we or others are no longer able to relieve their suffering." ${ }^{14}$ [Two oncologists]

"We've managed to preserve the Hippocratic tradition for 2,400 years. I see respect for life as cultural old growth forest. It's something we've fought hard to protect." ${ }^{15}$ [A palliative care physician]

"We never want patients to wonder whether their doctor will be trying to heal or trying to kill."16 [Specialty not specified]

"When a person says, 'I want to die'; it may simply mean, 'I feel useless.' When a person says, 'I don't want to be a burden'; it may really be a question, 'Am I a burden?' When someone says, 'I might as well be dead'; they may really be saying, 'No one cares about me'..."17 [Specialty not specified]

"I have had patients who begged me to put an end to their incredible suffering and meant it. I would have complied with their wish if the law had allowed me, but I had to say time and again that under the current law I would lose my license, get a criminal record and go to jail. All I could do was to ameliorate their suffering to the best of my ability and face every day how little that was." ${ }^{18}$ [Retired family physician] 
deliberately hastened death (Box 3). Within this discourse were several distinct messages:

- Advances in the science of pain management mean patients need not fear a painful death;

- When suffering cannot be alleviated, palliative sedation is an ethically preferable last-resort option;

- The end of life is an important time filled with potentially

\section{Box 2: Distinguishing euthanasia from other end-of-life} medical practices

"Of course, the euthanasia elephant in every palliative-care centre is how accelerated death is a routine procedure, albeit labeled as withheld treatment or a painkilling medication overdose. More than $80 \%$ of the Quebec doctors in the aforementioned survey [Fédération des médecins spécialistes du Québec] say some form of euthanasia is quietly practiced now." ${ }^{19}$ [Not authored by a physician; referring to Quebec doctors in general]

The change [to existing legislation] would protect doctors who withhold treatment or boost painkillers to end suffering and hasten the end, according to [a representative of the Collège des médecins du Québec]. "Doctors do their best to give appropriate care, knowing it could sometimes be interpreted as a crime in the Criminal Code," [representative] said. "Appropriate care should not be defined as murder."20 [Specialty not identified]

"...much of what the pro-euthanasia camp wants, such as the right for withdrawal of treatment and the administration of pain medication that might hasten death, is actually already available to terminally ill patients in Canada."21 [Palliative care physician]

\section{Box 3: Palliative care advocacy}

"Painkillers and sedation can make dying comfortable and painfree... Palliative care physicians would say that good palliative care obviates the need for euthanasia or physician assisted suicide."22 [Palliative care physician]

"Excellent palliative care is available in this country, so no one needs to fear dying in excruciating pain or indignity." ${ }^{23}$ [Specialty not specified]

"Dying in hospice, surrounded by loved ones, with good symptom control, can actually be a beautiful thing to witness... We believe that palliative care is a better option." ${ }^{16}$ [Family physician]

"The marginalization of palliative care - it has been low priority in the health-care system for years - pushes the debate toward euthanasia. A more intense and efficient use of palliative care resources both in the community and hospital would permit a more dignified death with optimal pain and symptom management and reduction of unnecessary and prolonged suffering." ${ }^{24}$ [Palliative care home care physician]

"Most of our patients there died a 'good death': their symptoms well controlled, serene and not alone...But, despite all our expertise and resources, there were some patients we were unable to help. They died horrible deaths: howling and writhing in pain, gasping for air, suffocating and being terrified...To let even a few people die a horrible death is unacceptable and inhumane. Assisted suicide and euthanasia must be an [sic] options." ${ }^{25}$ [Palliative care physician] meaningful opportunities that are lost when death is deliberately hastened.

The palliative care discourse sought to redirect the debate about euthanasia to a social discussion about how to improve access to and availability of quality end-of-life care for all Canadians. Palliative care physicians appeared critical of the larger medical community for lacking basic competence in symptom management as well as in the supportive accompaniment of dying patients. They also appeared critical of the larger health care system for marginalizing palliative care, suggesting that if palliative care were a mainstream practice, euthanasia would not be required (Box 3).

The messages conveyed by the palliative care discourse were uniform within our physician data, with 2 notable exceptions. For one retired palliative care physician and euthanasia advocate, palliative care was a values-based practice that should not be imposed on uninterested individuals. Another physician described her experience of caring for patients in a residential palliative care facility as confirming for her the importance of euthanasia as a necessary end-of-life care option (Box 3).

\section{Interpretation}

Although medical professional bodies in the province of Quebec appear in the media as largely supporting a movement toward the legalization of euthanasia, our data showed that the voices of individual physicians were represented as largely opposed. The 3 predominant discourses that recurred included claims about the incommensurability of euthanasia with the basic mission of medicine, a need to define end-of-life medical practices to disentangle the ethics of unique practices and advocacy for the development of palliative care.

Physicians in our sample frequently appeared in the print media with a stated purpose of clarifying ethical and practical distinctions between euthanasia and other medical practices. Conceptual confusion and definitional ambiguity concerning euthanasia and other medical practices have been reported internationally. In a content analysis of how euthanasia appeared in Dutch newspapers, almost 1 out of every 4 newspaper articles used the term euthansia to refer to a practice outside of the scope of Dutch law (e.g., the withholding of potentially life-prolonging treatment). ${ }^{26}$ These authors cautioned that such "definitional variability is likely to feed misunderstanding and confusion in public debates" (p. 6) and that a "shared understanding of key concepts and terminology" is necessary for the development of effective public health policy. ${ }^{26}$

The idea that palliative care, as a discipline, is opposed to acquiescing to euthanasia requests is not new. Indeed, the very definition of palliative care includes a statement that it neither hastens nor postpones death. ${ }^{27}$ In response to recent events in Canadian society concerning euthanasia, the Canadian Hospice Palliative Care Association urged that the discussion be refocused on how to improve access to quality end-of-life care for all Canadians. ${ }^{28}$ In our study, some physicians took this claim one step further: they claimed that good palliative care obviates the relevance of euthanasia because of its ability to alleviate suffering at the end of life. This stance is an expression of the non- 


\section{OPEN}

necessity argument, identified by the authors of a bibliographic analysis of euthanasia in palliative care journals. ${ }^{29}$ The nonnecessity argument purports that as long as effective palliative care is provided (and as long as there is still an increase in knowledge and expertise in this field of care), the discussion about legalizing euthanasia is useless and superfluous. (p. 523) ${ }^{29}$

Importantly, these same authors also identified a less prevalent and contradictory argument within the palliative care literature: the "fallibility of palliative care" (p. 524). ${ }^{29}$ This argument is advanced by those who work in palliative care, and who do not believe that palliative care can relieve suffering and provide for a painless and peaceful death in all cases. Interestingly, in a recent $C M A 7$ blog published on the eve of the Supreme Court Hearing of Carter v. Canada, Chochinov and Mount wrote that "To be clear, palliative care is not a panacea that can eliminate every instance and every facet of end-of life suffering." ${ }^{30}$ They went on to argue that palliative care does provide for a dignity-conserving model of care that, for many people, can effectively reduce a desire for euthanasia.

Taken as a whole, the public is likely to conclude that physicians (with some noted exceptions, especially in Quebec) are by and large opposed to the practice of euthanasia. Yet, this seems to run counter to the general public's attitudes about making euthanasia a legal option in Canada. With this in mind, there should be some concern that the media's portrayal of physicians as opposed to euthanasia could, ironically, undermine the public's trust in the profession, which is perceived as unlikely to support their wishes at the end of life.

\section{Limitations}

Our analysis does not make definitive claims about what physicians think about euthanasia. Our analysis is based on the portrayal of physicians within newspaper print media presentations shaped by actors located outside of the medical world (e.g., journalists, newspaper editors). In fact, it is possible that the voices of physicians who support euthanasia are underrepresented in the media because of fears about how their patients and colleagues might respond to their opinions while it is still illegal. In the United Kingdom, where euthanasia is not legally permitted, studies have found that physicians are largely unsupportive of the practice. ${ }^{3}$ However, in Belgium where euthanasia is a legal practice, physicians by and large express their support. ${ }^{4}$ This is an indication that willingness to support the practice publicly may depend in part on its legality and permissibility in the physician's jurisdiction.

\section{Conclusion}

These representations are read by the media-consuming Canadian public and likely interpreted and understood as how physicians as a group feel about euthanasia, with few ways for the public (or other physicians) to construct any counter narratives to this portrayal. Physicians, whose profession is considered to be expert and authoritative on the matter of euthanasia, hold a privileged place in society for swaying public opinion on this issue. Professional physician organizations and those vocal few who have engaged with the media are de facto representing physicians on public contemporary debates about euthanasia. It is vital for physicians to be aware of this public debate, how they are being portrayed within it, and its potential effects on impending changes to provincial and national policies.

\section{References}

1. Schafer A. Physician assisted suicide: the great Canadian euthanasia debate. Int 7 Law Psychiatry 2013;36:522-31.

2. Wilson DM, Birch S, MacLeod R, et al. The public's viewpoint on the right to hastened death in Alberta, Canada: findings from a population survey study. Health Soc Care Community 2013;21:200-8.

3. McCormack R, Clifford M, Conroy M. Attitudes of UK doctors towards euthanasia and physician-assisted suicide: a systematic literature review. Palliat Med 2012;26:23-33.

4. Smets T, Cohen J, Bilsen J, et al. Attitudes and experiences of Belgian physicians regarding euthanasia practice and the euthanasia law. 7 Pain Symptom Manage 2011;41:580-93.

5. Rietjens JAC, van der Maas PJ, Onwuteaka-Philipsen BD, et al. Two decades of research on euthanasia from the Netherlands. What have we learnt and what questions remain? 7 Bioeth Inq 2009;6:271-83.

6. Van Der Maas PJ, van Delden JJM, Pijnenborg L, et al. Euthanasia and other medical decisions concerning the end of life. Lancet 1991;338:669-74.

7. Canadian Medical Association. MD views on ethanasia, assisted suicide vary widely: survey. Canadian Medical Association Bulletin 2013;184:357.

8. O'Connor M, Payne S. Discourse analysis: examining the potential for research in palliative care. Palliat Med 2006;20:829-34.

9. Hodges BD, Kuper A, Reeves S. Discourse analysis. BMF 2008;337:a879.

10. Lupton D. Discourse analysis: a new methodology for understanding the ideologies of health and illness. Aust F Public Health 1992;16:145-50.

11. Collège des médecins du Québec. Le médecin, les soins appropriés et le débat sur l'euthanasie : document de réflexion. Montréal: le Collège; 2009.

12. Anonymous. Euthanasia supported in special cases. The Sherbrooke Record 2009 Nov 4:3.

13. Seguin R. Quebec man pleads for the right to die with dignity. The Globe and Mail [Toronto] 2009 Mar 9;Sect A:6.

14. Anonymous. Many professionals oppose euthanasia [editorial/op-ed]. The Montreal Gazette 2010 Aug 17; Sect A:14.

15. Anonymous. Physician fights right-to-die law; palliative care doctor opposed to assisted suicide. Kamloops Daily News 2012 Mar 16;News Sect A:5.

16. Bright H. Down a dangerous path. The Chilliwack Progress 2012 June 28;Letters. Available: www.theprogress.com/opinion/letters/160706495 (accessed 2015 Mar. 10).

17. Toffler WL. Doctor's experience shows other angle to wishes of death. Victoria News 2011 July 1;Opinion:9.

18. Terwiel M. A sensible and humane decision on helping the dying. Maple Ridge News 2012 June 22;Opinion:1.

19. Martin D. Hospice better than euthanasia. The Courtenay Comox Valley Record 2009 Dec 29; Opinion:23.

20. Perreaux L. Quebec medical college cautiously endorses limited euthanasia. The Globe and Mail [Toronto] 2009 Nov 4;National News. Available: www.theglobe andmail.com/news/national/quebec-medical-college-cautiously-endorses-limitedeuthanasia/article4215254/ (accessed 2015 Mar. 10).

21. Shufelt T, Couvertte P. Right-to-die debate escalates over proposed legislation. The Ottawa Citizen 2009 July 17;News Sect A:1.

22. Wiseman R. A better way to die. Calgary Herald 2010 Nov 21; Context Sect B:3.

23. Askin J. Only MDs who pledge never to kill can be trusted. National Post [Toronto] 2012 June 20;Letters Sect A:13.

24. Dworkind MA. Re: "Euthanasia advocates are dead wrong." The Gazette 2009 July 22;Editorial/Op-Ed Sect A:16.

25. Dauphinais C. Re: Whose suffering does euthanasia alleviate? National Post [Toronto] 2011 July 22;Letters Sect A:13.

26. Rietjens JAC, Raijmakers NJH, Kouwenhoven PSC, et al. News media coverage of euthanasia: a content analysis of Dutch national newspapers. BMC Med Ethics 2013;14;11.

27. World Health Organization. WHO definition of palliative care. Available: www .who.int/cancer/palliative/definition/en/ (accessed 2014 Nov. 29).

28. Canadian Hospice Palliative Care Association. Let's talk about hospice palliative care first. Available: www.chpca.net/hpcfirst (accessed 2015 Feb. 20).

29. Hermsen MA, ten Have HAMJ. Euthanasia in palliative care journals. 7 Pain Symptom Manage 2002;23:517-25.

30. Chochinov HM, Mount BM. Physician hastened death: awaiting a verdict. In: CMA7 Blogs 2014 Oct. 14. Available: http://cmajblogs.com/physician-hastened -death-awaiting-a-verdict/ (accessed 2015 Feb. 20).

Affiliations: School of Nursing (Wright), Faculty of Health Sciences, University of Ottawa, Ottawa, Ont.; Biomedical Ethics Unit (Fishman), Faculty of Medicine, McGill University; Department of Sociology (Karsoho), McGill University; Faculty of Medicine (Sandham), McGill Uni- 
versity; Division of Oral Health and Society (Macdonald), Faculty of Dentistry, McGill University, Montréal, Que.

Contributors: David Wright, Jennifer Fishman and Mary Ellen Macdonald contributed to conception and design, analysis of data and writing of the manuscript. David Wright wrote the first draft of the manuscript. Hadi Karsoho and Sarah Sandham contributed to acquisition and analysis of the data and writing of the manuscript. All of the authors approved the final version submitted for publication and agreed to act as guarantors of the work.
Funding: This research was funded by an operating grant from the Canadian Institutes of Health Research.

Acknowledgements: The authors would like to acknowledge our colleague and collaborator, Carolyn Ells, for her insights about our data.

Supplemental information: For reviewer comments and the original submission of this manuscript, please see www.cmajopen.ca/content/3/2/ E134/suppl/DC1 